\title{
The RED Teams as Institutional Mentors: Advice from the First Year of the "Revolution"
}

\section{Dr. Jeremi S. London, Arizona State University, Polytechnic campus}

Dr. Jeremi London is an Assistant Professor of Engineering at Arizona State University. She holds B.S. and M.S. degrees in Industrial Engineering and a Ph.D. in Engineering Education, all from Purdue University. Prior to her $\mathrm{PhD}$, she worked in quality assurance and logistics roles at Anheuser-Busch and GE Healthcare, where she was responsible for ensuring consistency across processes and compliance with federal regulations. For four consecutive summers (2011-2014), she worked in the National Science Foundation's Division of Undergraduate Education on research and evaluation projects related to the use of technology in STEM education. Dr. London masters mixed methods and computational tools to address complex problems, including: science policy issues surrounding STEM learning in cyberlearning environments; evaluation and impact analysis of federal investments in R\&D; and applications of simulation $\&$ modeling tools to evaluate programs.

\section{Dr. Edward J. Berger, Purdue University, West Lafayette (College of Engineering)}

Edward Berger is an Associate Professor of Engineering Education and Mechanical Engineering at Purdue University, joining Purdue in August 2014. He has been teaching mechanics for nearly 20 years, and has worked extensively on the integration and assessment of specific technology interventions in mechanics classes. He was one of the co-leaders in 2013-2014 of the ASEE Virtual Community of Practice (VCP) for mechanics educators across the country. His current research focuses on student problem-solving processes and use of worked examples, change models and evidence-based teaching practices in engineering curricula, and the role of non-cognitive and affective factors in student academic outcomes and overall success.

\section{Dr. Cara Margherio, University of Washington}

Cara Margherio is the Senior Research Associate at the UW Center for Evaluation \& Research for STEM Equity (CERSE). Cara serves as project manager for program evaluation on several NSF- and NIH-funded projects. Her research interests include community cultural wealth, counterspaces, peer mentoring, and institutional change.

\section{Dr. Elizabeth Litzler, University of Washington}

Elizabeth Litzler, Ph.D., is the director of the University of Washington Center for Evaluation \& Research for STEM Equity and an affiliate assistant professor of sociology. She directs research and evaluation projects from conceptualization, methodological design, and collection of data and analysis to dissemination of findings. Dr. Litzler is a member of ASEE and a former board member of the Women in Engineering ProActive Network (WEPAN). Her research interests include the educational climate for students in science and engineering, and gender and race stratification in education and the workforce.

Jennifer Branstad, University of Washington 


\title{
The RED Teams as Institutional Mentors: Advice from the First Year of the "Revolution"
}

\begin{abstract}
Engineering and computer science departments funded by the National Science Foundation's Revolutionizing Engineering Departments (RED) program are charged with taking a revolutionary approach to addressing a local need and with becoming national models for enacting systemic change. While the differences between geographically-dispersed RED teams and the schools in which they are embedded are palpable, there are parallels in the experiences that illuminate valuable lessons that can be shared across teams and with other departments. By sharing information and experiences across organizational boundaries, RED teams collaboratively problem-solve common issues and become mentors for others interested in embarking on a revolution. In this paper, we examine the first cohort of six RED teams as an example of "institutional mentoring." We define institutional mentoring as a type of peer mentoring among groups in which knowledge exchange is highly reciprocal, and institutional contexts and local challenges are explicitly considered when problem-solving. Observation notes taken during annual RED Principal Investigators meetings and focus group discussions among RED teams were qualitatively analyzed for themes. This analysis highlighted four broad categories of advice that are transferable across organizational boundaries: forming strategic partnerships, establishing a successful team, managing the project while maintaining flexibility, and working within organizational and academic constraints. Such insights are valuable for perspective RED teams and other interested in revolutionizing their engineering and computer science department.
\end{abstract}

\section{Introduction}

Traditionally, peer mentoring is a collaborative mentoring relationship between similarly situated individuals working towards similar goals. Peer mentoring groups are collaborative, reciprocal groups in which all participants are expected to share information and experiences, and contribute to brainstorming and problem-solving. As with traditional hierarchical mentoring, peer mentoring includes both instrumental support and psychosocial support. While usually discussed as an activity among individuals, we contend that this type of mentoring can also occur as an interaction between groups of non-co-located people engaging in similar endeavors. We call this mentoring institutional mentoring - a type of group peer mentoring that is informed by sociocultural models of learning, organizational knowledge transfer, and peer mentoring.

This paper presents the RED teams as an example of how institutional mentoring can occur. The National Science Foundation's Revolutionizing Engineering Departments (RED) program is unlike any other national initiative focused on undergraduate STEM education. In addition to 
providing schools with resources to incite "revolutionary" change within engineering or computer science departments, RED teams are expected to serve as national models for addressing systemic issues and instigating sustainable change in engineering and computer science education. The RED program's portfolio currently includes two cohorts composing thirteen geographically-dispersed teams using unique change strategies to address local challenges shaped by institution-specific factors. ${ }^{1}$

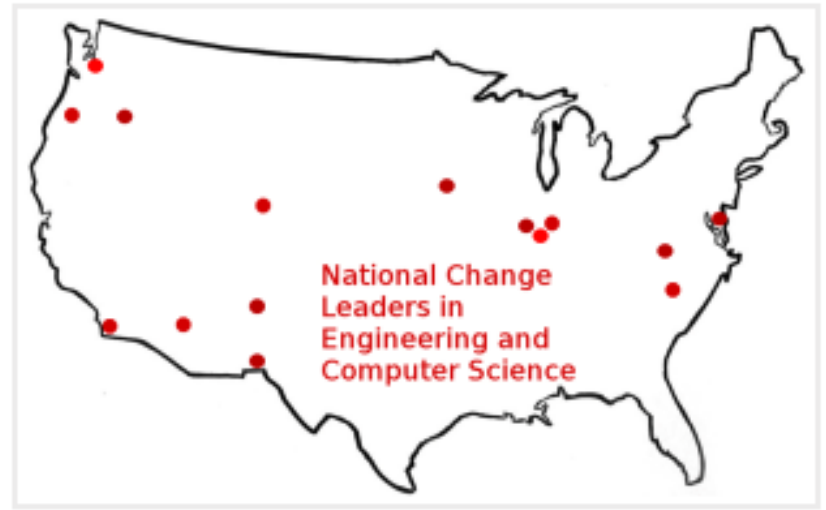

Figure 1. Geographic Distribution of RED Teams in 2015 \& 2016 Cohorts

The RED Consortium's programmatic activities occur throughout the year, and are designed to foster community within and across the cohorts of RED teams. Included in the program are annual PI meetings and monthly multi-team meetings in which the teams discuss the change strategies they are using to address local challenges. During these meetings, the teams discuss barriers they are facing and brainstorm potential solutions. While the differences between teams and the schools in which they are embedded are palpable, there are parallels in the teams' experiences across sites that illuminate valuable lessons that can be shared across teams and with other schools and departments that do not have RED grants.

By sharing information and experiences across organizational boundaries, RED teams serve as institutional peer mentors to each other. We define institutional mentoring as a type of peer mentoring among groups in which knowledge exchange is highly reciprocal, and institutional contexts and local challenges are explicitly discussed and taken into consideration when strategizing and problem solving. Using data collected from the annual and monthly meetings as well as focus groups with the first cohort (2015) of six RED teams we synthesized themes around transferrable advice between RED teams and to the broader community. While the advice

\footnotetext{
${ }^{1}$ The RED teams are located at the following institutions: Arizona State University (2015); Boise State University (2016); Colorado State University (2015); Iowa State University (2016); Oregon State University (2015); Purdue University (2015); Rowan University (2016); University of Illinois at Urbana Champaign (2016); University of New Mexico (2016); University of North Carolina at Charlotte (2015); University of Texas at El Paso (2016); University of San Diego (2015); Virginia Tech University (2016). Project summaries can be found here:

https://academicchange.org/red/nsf-project-summaries?iframe=true\&theme preview=true.
} 
was presented in a way that any prospective RED team may benefit, institutional factors are important to consider when operationalizing the advice in a particular context.

\section{Background}

The conceptual framework of this paper draws from three sets of literature: educational environment models of learning, organizational knowledge transfer, and peer mentoring. In the following sections, we briefly outline each paradigm and then use these theoretical underpinnings to define the construct of institutional mentoring.

\section{Educational Environments}

Learning is the product of interactions between individuals and their educational environments. College impact models focus on the multifaceted relationships between student background, educational environment, and student outcomes. In higher education, educational environments include not only the classroom setting, but also institutional and cultural factors such as size and selectivity of institution, type of institution (research university, teaching college, etc.), the locus of control (i.e. private or publically funded), demographics of the institution, policies, cocurricular programs, and culture of the university at large ${ }^{1}$. These factors are linked to student outcomes such as learning and persistence. Lattuca and Litzinger ${ }^{1}$ note that these characteristics can be quite complex in higher education settings as departments and other sub-units are embedded within larger institutional contexts. Following Holland's theory of career environments, they assert that "academic environments are socializing mechanisms, reinforcing and rewarding different patterns of abilities, interest, and values, while simultaneously discouraging others" (p. 480). As educational environments are pivotal for student outcomes, education practitioners, including curriculum designers, need to consider these factors when designing programs for students. Additionally, researchers should reflect on these factors when evaluating the effect of programs or institutions on student outcomes.

\section{Organizational Knowledge Transfer}

Management literature on organizational knowledge transfer emphasizes ways in which knowledge is shared across organizational boundaries and between organizational units to enhance performance and innovation ${ }^{2}$. Organizational knowledge transfer is "the process through which organizational actors - teams, units, or organizations - exchange, receive and are influenced by the experience and knowledge of others",2 (p. 832). Knowledge type, and organizational and social characteristics affect how knowledge transfer works. Tacit, specific, and complex knowledge can negatively affect shareability because of time constraints and the difficulty of sharing such intricate knowledge. In terms of organizational characteristics, new and burgeoning units are expected to benefit more from knowledge transfer than older units because processes within older units are more entrenched and difficult to change. On the dyadic level, the strength of social ties and social trust facilitate knowledge sharing since both contribute to the 
partners' commitment and willingness to help each other. Lastly, cognitive dimensions of social capital —including shared systems of meanings, common goals, and similar ways of actingfacilitate knowledge transfers as they "promote mutual understanding" across units and help knowledge integration. In other words, sharing information across culturally similar organizations is often more successful than sharing information across culturally different organizations. Similarly, Argote and Ingram ${ }^{3}$ note that understanding organizational context is important for analyzing knowledge transfer because knowledge from one situation may not apply in a different context. When tasks, or contexts for those tasks, are similar, there is a greater likelihood that knowledge can successfully be shared between groups.

\section{Peer Mentoring}

In contrast to traditional, hierarchical-dyadic models of mentoring, peer mentoring groups are small collections of individuals who meet regularly to provide feedback on work, share experiences and information, problem solve, and lend support to one another. Peer-mentoring groups are based on the premise that all participants have something to give and something to gain from the group ${ }^{4,5}$, and norms of reciprocity dictate that all members of a peer mentoring group should give and receive benefits. Peer mentoring includes two functions: instrumental support, including codified knowledge and advice, and psychosocial support, including role modeling, friendship, and counseling. Peer mentoring often includes sharing experiences and information from different sources, a place to work through intellectual and personal matters, a safe space to try out ideas and gain feedback, goal setting and project tracking, and reduced feelings of isolation due to positive identification with a group. Peer mentoring emphasizes the collaborative and reciprocal nature of collections of similarly situated individuals working towards similar goals. The focus is not on teaching one another, but rather on sharing experiences that emphasize learning and support.

Peer mentoring groups are common among academic faculty members and researchers working

towards tenure ${ }^{4,6-10}$. Peer mentoring in the academic setting has been shown to increase the completion of projects, promotion in academic rank, and continued enthusiasm for their career ${ }^{7}$. Peer mentoring is also common in other organizational settings and has been shown to have positive effects on compensation and promotion ${ }^{12}$. In particular, research shows that peer mentoring during the early years of career development is beneficial for developing competency and professional identity ${ }^{5}$.

\section{Conceptual Model: Institutional Mentoring}

The proposed conceptual model of this study combines aspects of environmental models of learning, organizational knowledge transfer, and peer mentoring to suggest the paradigm of institutional mentoring within academia. From the literatures on environmental models of learning and organizational knowledge transfer, we focus on the contextual factors that shape the 
way that knowledge can be shared across organizational boundaries through institutional mentoring. We define institutional mentoring as a type of peer mentoring between teams at different institutions working towards similar goals in which knowledge exchange is highly reciprocal, and institutional contexts and local challenges are explicitly considered when problem-solving. Institutional mentoring emphasizes both individualized solutions to local constraints and resources, as well as generalized "lessons" that apply across all contexts.

Additionally, we contend that institutional mentoring provides psychosocial support between non-co-located groups facing similar challenges. In addition to sharing discrete sets of knowledge, groups participating in institutional mentoring also provide psychosocial support to each other.

Institutional mentoring can help groups and group members develop a sense of belonging to a larger collective movement working towards difficult institutional changes, often in the face of resistance. Figure 2 provides a depiction of institutional mentoring. While some parts of the image may be self-explanatory, some characteristics might need an explanation. In short, the figure shows how institutional can occur among multiple groups at different institutions simultaneously. Movement toward a similar target is what unites the groups. While there may be some overlap, each institution has a unique context (e.g., policies, practices, cultural norms) that distinguish them from one another. Information can flow in all directions. Given these differences, some insights shared across groups may easily permeate an institutional and can be readily adapted; while in many other cases, some work is required to adapt the insights from other mentor groups to a new context.

A particular challenge in institutional mentoring is the lack of a common vocabulary for the mentor groups in describing their institutional context. Higher education institutional classification systems exist, but they typically compare easy-to-measure surface features such as enrollment, faculty size, research volume, and so forth. The Carnegie Classification ${ }^{14}$ is an example of one such system. There have been other efforts involving system dynamics models ${ }^{15,16}$ for higher education, but these models suffer from a typical problem: the role of unmodeled dynamics in dictating the system response. In higher education institutions, these unmodeled dynamics encompass relationships, collaborations, personalities, history, and decision-making practices (i.e., institutional politics), all of which are driven by human interaction and vary greatly from institution to institution. There are specific areas of higher education, such as student affairs organizations, which have developed a taxonomy based upon collaborations and relationships. The Models of Student Affairs Practice Inventory ${ }^{17}$ has defined 
a controlled vocabulary that can be used to describe a particular institutional context for student affairs work. While valuable for describing student affairs organizations, this taxonomy is not generalizable to the broader workings of the institution; but it did inform our thinking about issues of context we should consider.

\section{Research Questions}

This conceptual framework for institutional mentoring inspires a number of questions about how such a mentoring relationship could be operationalized. These questions relate to the kinds of information that are valuable to share, the mechanisms by which they are shared, and the applications of that information within a different context. As such, we ask the following questions:

(1) What advice is transferrable from one RED team to another, and to the broader engineering education community, on how do we enact a sustainable revolution?

(2) What advice is context-dependent and what is the relevance of the advice for adaptation by other schools?

\section{Methods}

Before we describe our methodological approach, it is important for us to be clear about the positionality of the authors. London and Berger are members of two separate RED teams, and Margherio, Litzler, and Branstad are part of REDPAR (RED Participatory Action Research), an NSF-funded project to study the process of change within the RED schools. We utilized an insider methodological approach, in part because of London and Berger's affiliations. Insider research is typically conducted by researchers who are currently members of the group they wish to study ${ }^{18}$. This approach afforded us an in-depth view into how group context facilitates (or hinders) the team's success - each of the insiders has significant access to the group processes involved in the grants. Further, insider positionality lends itself to studying the process, rather than the outcome, of practice ${ }^{19}$.

For this paper, we focused only on the six universities in the first cohort of NSF RED grant recipients. Data sources included audio recordings of virtual focus groups with five of the six first cohort RED teams (one team declined to participate) conducted in the winter of 2017, and observation notes from the 2016 RED PI meeting. The focus group transcripts were the only data that was collected expressly for this paper. In the results section below, we do not connect quotes with particular teams, in order to maintain confidentiality.

Both data sets were analyzed using thematic analysis. Analysis began with the detailed notes taken during the RED PI meetings and webinars, which were qualitatively coded for emergent 
themes. After an initial reading of the documents, a list of major themes was generated. Codes were refined using an iterative process. Particular attention was paid to issues that cut across institutions and instances in which participants were able to generalize their experiences to share with other participants in the meetings.

We asked each RED team to have at least three members on the virtual focus group, ideally the PI or co-PI, the engineering education specialist and the social scientist. The focus groups were approximately 30-minutes long and were recorded and transcribed for analysis. Focus group sessions used a common set of six questions broken into two areas: 1) general lessons learned and promising practices that could be adopted by others seeking to make change, and 2) reflection on the context-specific factors at their institution that promote or inhibit change. After conducting the first two focus groups, we assessed and refined the focus group protocol. The "insider" research team members did not conduct the focus groups with their own teams. The five focus group transcripts were coded by London and Berger (the insiders). Each coder identified emergent themes via open coding, resulting in dozens of individual codes. The coders then collaborated to coalesce the initial code set into a reduced and more meaningful set of codes.

\section{Results}

Four broad categories of knowledge were shared across institutional boundaries during annual and monthly meetings, and reiterated during the focus groups. RED teams described strategies for building successful alliances and partnerships, establishing the RED team and organizing workload, project management in the face of changing contexts, and working within organizational and academic constraints. In the following section, these themes are discussed using both the meeting notes and the transcripts from the focus groups.

Annual PI meetings and monthly calls

During the monthly teleconferences and annual PI meeting, teams shared advice that was transferable across organizational barriers. Throughout the meetings and calls, participants stressed the importance of fostering a sense of commitment and engagement at multiple levels of organizational leadership, as well as getting and staying organized to manage large, complex and evolving projects. Table 1 outlines the key themes that appeared in the meeting notes, and a brief discussion of several key themes with relevant quotes is given next.

Table 1. Themes derived from Annual and Monthly Meetings

Buy-In and Support at All Levels of Leadership Hierarchy (Strategic Partnerships)

description: Defining the changes each program seeks to create, working to establish buy-

in across organizational barriers, and dealing with the "risks" of big, 


\begin{tabular}{|r|c|}
\hline & systematic change \\
\hline advice: & $\begin{array}{l}\text { Establish early buy-in at all levels of leadership hierarchy--from } \\
\text { faculty members to school administrators--to facilitate continued } \\
\text { engagement. }\end{array}$ \\
\hline Establishing the RED Team and Initial organization \\
\hline description: & Establishing a team with a diverse set of skills \\
\hline advice: & \begin{tabular}{l} 
- $\quad \begin{array}{l}\text { Bring a social scientist onto the team as early as possible } \\
\text { Create sub-teams, assign tasks, and define roles that play to team } \\
\text { members' strengths. }\end{array}$ \\
\hline Project Management and Maintaining Flexibility
\end{tabular} \\
\hline description: & $\begin{array}{l}\text { Defining a workflow and establishing deadlines for accountability, while also } \\
\text { maintaining flexibility to deal with internal and external changes. }\end{array}$ \\
\hline advice: & $\begin{array}{l}\text { Do not underestimate the time different elements of the project, like } \\
\text { assessment, will take. }\end{array}$ \\
& $\begin{array}{l}\text { Have a plan and start early. } \\
\text { Respond with flexibility to external changes that cannot be foreseen; } \\
\text { use the proposal as a guide rather than a prescription. }\end{array}$ \\
\hline Working within Organizational and Academic Constraints
\end{tabular}

The meeting notes emphasized the importance of fostering commitment and engagement while maintaining flexibility to deal with internal and external changes. In particular, members of the RED teams discussed both the importance of ownership and strategies for getting faculty members at different stages of their careers involved in the project. For example, one team member noted, "We started with the department retreat to get buy-in and we got them to contribute to the ideas so there was a sense of ownership." Another individual spoke to appeals focused on career stage, advising, "At lunch, talk with your junior faculty about how they can plug into the grant. We can help move it along. Give them a short RED spiel they can put into their proposal." During the monthly RED conference calls, individuals stressed the importance of not only building buy-in by appealing to the concerns of faculty members, but also of being upfront with information about the project and clearly communicating to all those involved. For example, one team member noted that, "you've got to make the information digestible and not secret." 
In addition to establishing commitment and buy-in, teams discussed the need to be flexible in response to changing circumstances, like faculty turnover and/or turnover at the institutional level. One team member eloquently summed up this sentiment by stating:

You might be tempted to think of the proposal like a prescription, but it is better to think

of it as a vessel that has to deal with swells, strong winds etc. and therefore the work is an emergent process undertaken by a community and can't follow a strict prescription.

In addition to comprehensive advice around defining problems and establishing buy-in, RED teams readily shared guidance regarding the importance of building the "right" team, defining roles and tasks, and creating internal markers to guide the flow of work. Teams were quick to acknowledge the importance of having people with diverse expertise and the importance of subteams in organizing the change process, because, as one individual at the PI meeting stated, "subteams make progress." This individual elaborated that sub-team organization increased efficiency because "people [pick] sub teams they wanted to be on, with less frequent team meetings."

RED team members also noted the importance of establishing meeting routines and deadlines to ensure consistent progress. At the PI meeting one team member suggested to "build things into the year so that you are accountable for things externally, which helps you keep making progress." During the monthly meetings it was noted that the core team meeting frequency may change throughout the project, as teams may need to meet more often at the beginning to design the project and establish roles, and less frequently as the project gets underway.

Insights from Focus Groups

The four categories of transferable advice were echoed in the focus group discussions (see Table 2). In particular, this set of advice illuminated generalizable insights on how to approach a RED project, as well as the importance of taking into account the local context of the institution by aligning the RED project with the existing institutional culture, priorities, and other initiatives to create lasting change. In addition, the focus groups elicited specific advice regarding the solicitation for the proposals.

\section{Context-independent advice}

Advice regarding the RED solicitation, building strategic alliances and partnerships, establishing a compatible RED team, and managing the project in the face of uncertainty resonated across institutional barriers. For instance, in discussing the importance of creating value-added partnerships and branding of the project, one team commented about partnering with personnel about their branding:

Yeah, for example, we had the communication liaison from the marketing office come in. She met with the RED team to talk about the website development so that we could make 
sure that the messages that the faculty were hearing were being consistently represented with the website and with the newsletter or magazine that goes out.

Moreover, leadership was cited repeatedly as being crucial to project success, both for leadership of the project itself but also because of the leaders' visibility within other areas of the institution. Another RED team noted:

I think the leadership on the project with the department chairs have helped us pick the right people who have the right visibility and respect within their departments to do things that make them visible and respected so that it's something that these faculty wanted to do and they can talk about it.

All the focus group participants talked about the importance of the start-up phase of the project, and the consensus advice was to simply "dive in". Consider this statement from a team member that emphasizes the continuous nature of revolutionary change:

I just want to emphasize that obviously, you have to start somewhere, You just have to dive in. I think what it is, is that assuming that there's a clear starting point is a bad idea because nothing really has a beginning, so to speak.

In addition, all the RED teams agreed on two points: (i) revolution takes time ("Some of the changes that we're hoping will take place are pretty big things, and you can't really do those very quickly."), and (ii) flexibility is critical ("The best plan, even grounded in theory, when you try to implement may not go as planned, and so stay adaptable. Modify where you need to...").

\section{The role of local context}

Each of the RED teams mentioned specific local, contextual factors at their institution that shaped their approach to revolutionary change. One team mentioned that history played an important role in how faculty members view their teaching mission:

We are dealing with two departments... and we both participate in the ...undergraduate program that we are applying these treatments to. I think [one] program, who knows what kind of historical reasons, is more of a hardcore. Where our [faculty believe that our graduates should work in the [specific] industry; our graduates should be top of the line; they should have great mathematical skills. They should be all great versus [the other] department has been formed with this idea of closer collaborations with the industry, applied research versus less applied research. I think for years these differences have been ingrained in the minds of the faculty, and that has the consequences on the attitudes towards teaching and attitudes towards helping students succeed, [how] they should really operate their classrooms. We are seeing I think the results of the years of some subtle differentiation between the departments now in implementation of this program. 
The implication is clear that faculty often maintain deeply-held beliefs related to history, and detaching faculty from their emotional connection to the status quo can be challenging. One approach to overcome this is to align the RED project with other ongoing institutional initiatives, as described by another RED team:

I think whenever you have large-scale changes that bring into light the identity of the school and the faculty as they're shifting and trying to find their place within this new terrain, that already creates a certain amount of feelings of unsettlement perhaps. Then to have an external catalyst, like RED, generate change and really mobilize change and lend legitimacy to the [leadership], certainly some people are very willing to jump on board, but other people feel afraid and unsure about what that might mean for them.

Finally, the scale of the institution itself can be a barrier to broadening participation in the revolution:

[B]ecause of the size of [the institution] and how many things are going on, there are a lot of initiatives, a lot of projects people are working on, which is fantastic but it also kind of overwhelms people in the sense that it's hard to really find momentum in something unless it keeps going, because there's always another initiative that's springing up that people latch on to. So it's a little bit of a challenge to keep people focused on something and follow through.

The main idea described here is 'initiative fatigue' in which the faculty and staff are already so deeply involved in other initiatives, all of which seem valuable to them, that it is hard to capture their attention and energy for (yet another) new activity.

Table 2. Themes derived from focus groups Advocates, allies, partnerships, and communication (Strategic Partnerships)

\begin{tabular}{|r|l|}
\hline description: & $\begin{array}{l}\text { Defining the role of all departmental stakeholders, targeting consistent } \\
\text { communication to stakeholders, and navigating the internal dynamics of the } \\
\text { institution including leadership and hierarchy. }\end{array}$ \\
\hline advice: & \begin{tabular}{l} 
Consider your definition of stakeholders as broadly as possible, erring \\
on the side of inclusivity, then communicate clearly and frequently. \\
- $\begin{array}{l}\text { Understand how decisions are made, and 'manage up' appropriately. } \\
\text { Recruit like-minded change agents from the faculty, while respecting } \\
\text { their other commitments and competing demands on their time. } \\
\text { - Moreover, engage all faculty in an honest and gentle way, with both } \\
\text { optimism and enthusiasm for the project. }\end{array}$ \\
\hline Establishing core RED Team \\
\hline description:
\end{tabular} \mid $\begin{array}{l}\text { Establishing a common vision among the core team, with an emphasis on } \\
\text { people, relationships, and expertise. }\end{array}$ \\
\hline advice: & C Create trusted partnerships among like-minded people who share a \\
\hline
\end{tabular}




\begin{tabular}{|c|c|}
\hline & $\begin{array}{l}\text { common vision for change, and make sure that team members have } \\
\text { both professional and personal compatibility. }\end{array}$ \\
\hline \multicolumn{2}{|c|}{ Strategy, planning, and start-up } \\
\hline description: & Managing and setting appropriate expectations for the project. \\
\hline advice: & $\begin{array}{l}\text { - Revolution takes time and flexibility, but you simply have to dive } \\
\text { into the project and start--quickly. } \\
\text { - Set reasonable expectations, because almost everything will take } \\
\text { longer than you think it will. } \\
\text { - Pay close attention to project management, and consider hiring a staff } \\
\text { person for this role. }\end{array}$ \\
\hline \multicolumn{2}{|c|}{$\begin{array}{l}\text { Project alignment with local expectations, culture, and other initiatives (Working within } \\
\text { contexts) }\end{array}$} \\
\hline description: & $\begin{array}{l}\text { Understanding history and larger institutional dynamics and priorities in } \\
\text { shaping your change initiatives. }\end{array}$ \\
\hline advice: & $\begin{array}{l}\text { - Remember that the status quo is what it is for a reason, and that } \\
\text { people sometimes have emotional attachments to the status quo. } \\
\text { - Change can be made more palatable when connected to larger } \\
\text { institutional priorities, mission, or strategic goals. }\end{array}$ \\
\hline \multicolumn{2}{|c|}{ Formal advice from the solicitation } \\
\hline description: & $\begin{array}{l}\text { Reading the RED solicitation, which contains vital advice to proposers, } \\
\text { including team roles, scoping "revolutionary" change, and potential foci. }\end{array}$ \\
\hline advice: & $\begin{array}{l}\text { - Think about the undergraduate experience as more than the } \\
\text { curriculum, then consider what significant, abrupt (i.e., revolutionary) } \\
\text { changes make sense for your setting. } \\
\text { - Be sure to watch the RED webinar. }\end{array}$ \\
\hline
\end{tabular}

\section{Discussion \& Conclusion}

Theme alignment

The alignment among the themes that emerged from the different data sources is remarkable and speaks to the commonality of experiences across the RED teams. All face tremendous challenges in implementing their ambitious agendas, and although the local context differs, all of the teams seem to share a common experience around partnerships and communication, forming and maintaining the core RED team, managing faculty, and starting up and managing the project. We believe these themes are highly time-dependent; data utilized in this paper came from year 1 and part of the way through year 2 of the first cohort of RED grants. We expect that if we were to continue to collect information about lessons learned and promising practices, we will see shifts in the themes as teams become more highly embedded in their own revolutions. 
Guidance from the RED teams takes on a temporal perspective as some advice is most relevant when first embarking on a RED-like revolution while the other is most useful after the revolution has begun. For example, both sets of results speak to the importance of getting buy-in and support from leadership and forming a well-rounded team with healthy team dynamics early in the process. Both data sets provide advice on how to manage the RED project after the project has begun, including advice about ways to interact with faculty, project management, and the importance of remaining focused yet flexible. Furthermore, both data sets highlight the importance of paying attention to the institutional context in which the project is happening. The contextual factors themselves may vary, but the advice to pay attention to them holds regardless of the specifics.

There is at least one notable difference between sets of advice from the meetings and calls, and the advice from the focus groups. The focus groups highlight the importance of referring to the contents of the RED solicitation and/or RED webinar. There are at least two reasonable explanations for this difference. One reason relates to timing of events: the RED webinar happened after the PI meeting and before the focus group sessions. It was an event that was specifically designed to build capacity among prospective RED teams. Additionally, focus groups were specifically asked about the advice they would provide to prospective RED teams whereas this was not a formal topic of discussion at the PI meeting. Thus, it is not surprising that the RED solicitation did not come up as a particularly helpful resource for teams who had already submitted RED proposals and awards.

\section{Implications for institutional mentoring}

Traditionally, mentoring involves an experienced person assisting a less-experienced person by offering psychosocial support, career development, and role modeling. Peer mentoring includes similar instrumental and psychosocial support, but without the hierarchical relationship. Although usually discussed as an activity among individuals, we propose that the RED teams have been part of an informal institutional mentoring activity as they interact across schools with other teams engaging in a similar endeavor. This concept of institutional mentoring, which is informed by literature on educational environments, organizational knowledge transfer, and peer mentoring has helped us understand the themes that were derived from the data collection. It is a distinct form of mentoring because insights on the institutional/contextual factors associated with the groups helps make sense of team experiences and understand how to translate salient insights across contexts.

The RED team monthly conference calls and annual PI meetings are routine parts of RED grant execution (although the focus groups were convened expressly to support this study). As such, they represent explicit opportunities for institutional mentoring convened by the RED consortium itself. The conference calls and PI meetings provide the kind of psychosocial support that is so important in mentoring relationships, as well as the operational support of advice, 
tactics, and approaches to RED project management and execution. These interactions are opportunities to build solidarity across teams, and we already see cross-RED-team sub-groups forming to explore specific issues of common interest across RED teams (with this study being one such example; there are others ${ }^{20}$ ).

Our understanding of this case of institutional mentoring is informed by our own positions as participants in this project as well by as this early data collection. We expect to continue this work in future years to understand the lessons learned by RED teams, especially as they become more engrossed in the transformational work of their grants. By serving as insider researchers, we can act as a conduit for the information that the RED teams are learning by sharing this information with the broader engineering and computing education communities. The RED teams themselves will also be sharing their own results and lessons learned which will be highly context dependent.

This paper presents the RED teams as an example of how institutional mentoring can occur and what type of information is shared during the start-up phase of a large transformational grant. In this study, RED teams shared reflections about the first year of their respective "revolutions". Despite notable differences between each RED teams' institutional context, themes emerged regarding advice they would give to prospective RED teams before embarking on their "revolution", and issues to consider once the "revolution" is underway.

\section{Works Cited}

1. Lattuca, Lisa R. and Thomas A. Litzinger. 2014. "Studying Teaching and learning in Undergraduate Engineering Programs." in Cambridge handbook of engineering education research. Eds. Johri, Aditya, and Barbara M. Olds. Cambridge University Press.

2. Van Wijk, Raymond, Justin JP Jansen, and Marjorie A. Lyles. "Inter- and intraorganizational knowledge transfer: a meta-analytic review and assessment of its antecedents and consequences." Journal of Management Studies 45.4 (2008): 830-853.

3. Argote, Linda, and Paul Ingram. "Knowledge transfer: A basis for competitive advantage in firms." Organizational behavior and human decision processes. 82.1 (2000): 150-169.

4. Bussey-Jones, Jada; David Malebranche; Bennet Lee. 2006. "Repaving the Road to Academic Success: The IMeRGE Approach to Peer Mentoring." Academic Medicine 81.7: 674-679.

5. Kram, Kathy E. and Lynn A. Isabella. 1985. "Mentoring Alternatives: The Role of Peer Relationships in Career Development." The Academy of Management Journal 28.1:110-132. 
6. Driscoll, Lisa G. et al. (2009). "Navigating the Lonely Sea: Peer mentoring and collaboration among aspiring women scholars." Mentoring \& Tutoring: Partnership in Learning 17.1:5221.

7. Files, Julia A. and Mayer, Anita. 2008. "Facilitated Peer Mentorship: A Pilot Program for Academic Advancement of Female Medical Faculty." Journal of Women's Health 17.6.

8. Mavrinac, Mary Ann. 2005. "Transformational Leadership: Peer Mentoring as a ValuesBased Learning Process." Libraries and the Academy 5.3:391-404.

9. Jackson, Vicki A; Palepu, Anita; Szalacha, Laura; Caswell, Cheryl; Carr, Phyllis L; Inui, Thomas. 2003. "Having the Right Chemistry": A qualitative Study of Mentoring in Academic Medicine." Academic Medicine 78.3.

10. Palermo, Claire; Roger Hughes; Louise McCall. 2010. "A Qualitative evaluation of an Australian public health nutrition workforce development intervention involving mentoring circles." Public Health Nutrition 14.8:1458-1465.

11. Santucci, Aimee K., Jennifer Lingler, Karen Schmidt, Beth Nolan, Dawn Thatcher, Deborah Polk. 2008. "Peer-Mentored Research development Meeting: A Model for Successful peer Mentoring Among Junior Level Researchers." Academic Psychiatry 32:493-497.

12. Allen, Tammy D. 2004. "Career Benefits Associated with Mentoring for Proteges: A MetaAnalysis." Journal of Applied Psychology 89.1:127-136.

13. Danksy, Kathryn H. 1996. " The effect of group mentoring on career outcomes" Group and Organization Management 21.1:5-21.

14. The Carnegie Classification of Institutions of Higher Education (n.d.). About Carnegie Classification. Retrieved (date January 10, 2016) from http://carnegieclassifications.iu.edu/

15. Kennedy, M. 2011. "A review of system dynamics models of education policy issues." Proceedings of the 24th International Conference on System Dynamics Society, Washington DC, USA.

16. Kennedy, M. and Clare, C. 1999. "Some Issues in Building System Dynamics Model for Improving the Resource Management Process in Higher Education", In Proceedings of the 17th International System Dynamics Conference, Wellington, New Zealand.

17. Manning, K., Kinzie, J. and Schuh, J. 2006. One Size Does Not Fit All: Traditional and Innovative Models of Student Affairs Practice. Routledge.

18. Dwyer, Sonya Corbin, and Jennifer L. Buckle. "The space between: On being an insideroutsider in qualitative research." International journal of qualitative methods 8.1 (2009): 5463.

19. Bonner, Ann, and Gerda Tolhurst. "Insider-outsider perspectives of participant observation." Nurse researcher 9.4 (2002): 7-19.

20. Lord, S., Berger, E., Kellam, N, Ingram, E., Riley, D., Rover, D., Salzman, N., and Sweeney, J. D. 2017. "Talking about a revolution: Overview of RED NSF projects." In Proceedings of the 2017 ASEE Annual Conference and Exposition, Columbus OH, June 2017. Paper ID $\# 19024$. 